\title{
MEASURING SYSTEMS ENGINEERING AND DESIGN THINKING ATTITUDES
}

\author{
Greene, Melissa T.; Gonzalez, Richard; Papalambros, Panos Y. \\ University of Michigan
}

\begin{abstract}
Systems engineering and design thinking have been widely seen as distinctly different processes, systems engineering being more data-driven and analytical, and design thinking being more humancentred and creative. We use the term 'design thinking' to encompass the plurality of human-centered design processes that seek to unpack the core values behind design decisions. With the increased awareness that both systems engineering and design thinking need each other, the effects of a possibly persisting distinction on engineers' attitudes toward these two processes are not well understood. In this paper, we describe the development and validation of a scale for measuring individual attitudes about systems engineering and design thinking. Thematic analysis of engineering and design literature is used to derive a Likert scale reflecting these attitudes. We use exploratory and confirmatory factor analysis to test and confirm this two-factor thematic representation, resulting in a 9-item Systems Engineering and Design Thinking Scale measure of attitudes.
\end{abstract}

Keywords: Design cognition, Design engineering, Human behaviour in design, Multi- / Cross- / Transdisciplinary processes, Systems Engineering (SE)

\section{Contact:}

Greene, Melissa Theresa

University of Michigan

Design Science

United States of America

greenemt@umich.edu

Cite this article: Greene, M.T., Gonzalez, R., Papalambros, P.Y. (2019) 'Measuring Systems Engineering and Design Thinking Attitudes', in Proceedings of the 22nd International Conference on Engineering Design (ICED19), Delft, The Netherlands, 5-8 August 2019. DOI:10.1017/dsi.2019.401 


\section{INTRODUCTION}

Systems Engineering (SE) and Design Thinking (DT) have been widely seen as distinctly different processes, systems engineering being more data-driven and analytical, and design thinking being more human-centred and creative. This may be attributable in part to differences in attitudes held by engineers and designers. Attitudes are sets of beliefs, emotions, and behaviours towards people, objects, processes, and events, that develop over time as the result of experience, education, and upbringing. Differences between engineering and design education, job functions, and organizational responsibilities create different perspectives about what design is and how best to do it, resulting in the potential misrepresentation of systems engineering and design thinking as opposing or mutually exclusive processes.

The presence and perception of design thinking processes in systems engineering has changed significantly in recent decades (Dym et al. 2005, Harvard Business Review 2015). Similarly, the design thinking community has recognized the need for more systems thinking as the complexity of design tasks at hand has increased (Greene et al. 2017). With the increased awareness that both systems engineering and design thinking need each other, the effects of a possibly persisting distinction on engineers' attitudes toward systems engineering and design thinking are not well understood.

This article uses a psychometric approach to understand systems engineering and design thinking attitudes and their relationship. The purpose of the work is to identify attitudes that reflect some attributes of a "systems engineering mindset" and a "design thinking mindset," and to challenge the assumption that these two perspectives are dichotomous. It describes the development and validation of an instrument called Systems Engineering and Design Thinking (SE\&DT) Scale that measures attitudes towards SE\&DT. Thematic analysis of the literature reflecting the traditional systems engineering vs. design thinking distinction is used to derive conceptual models of SE\&DT attitudes, supplemented by analysis of additional resources such as professional systems engineering handbooks, behavioural research in systems engineering, open-access resources on design thinking, and design science research. These conceptual models are represented as two subscales in a Likert scale questionnaire consisting of 23 statements about key themes in SE\&DT. The questionnaire was administered to 369 professional engineers and engineering students recruited through the social media platform Reddit. A second smaller panel of 88 experts was recruited through referral. We use Exploratory Factor Analysis (EFA) and Confirmatory Factor Analysis (CFA) to test the two-factor thematic representation of SE\&DT attitudes in the SE\&DT Scale. Strong model fit estimates in CFA confirmed the factor structure of the thematic analysis and exploratory factor analysis, and resulted in a final 9-item measure we called the SE\&DT Scale. This Scale can be used to identify the split conceptualization of designer attitudes, whether engineers or product designers, and point to opportunities for cross understanding and cognitive integration.

\section{MEASURING SYSTEMS ENGINEERING AND DESIGN THINKING ATTITUDES}

Systems engineering organizations like governmental mission agencies and manufacturing corporations are exploring opportunities for applying design thinking principles in systems engineering projects (Souza and Barnhöfer 2015; Darrin and Devereux 2017; McGowan et al. 2013; McGowan et al. 2017). Short courses or accelerated project experiences where engineers can learn design thinking methods through a hands-on design process and reflection are common. Some organizations have dedicated research groups for developing multidisciplinary approaches that include design thinking. This integrated process is often described as challenging, with varying levels of success due to differences between systems engineering and design thinking philosophies, methods, and tools.

Attitudes are often studied in the context of behaviour, with several theories suggesting that the link between attitudes and behaviour is a controlled and deliberative process. Systems engineers' attitudes about traditional engineering processes and design thinking processes (i.e., their "philosophies") can therefore influence both the implementation of these processes and their outcomes. By studying SE\&DT attitudes (as opposed to behaviours), we aim to offer additional insights on engineers' ability 
to apply design thinking principles and "act like designers" during systems engineering projects, as well as on classical product designers' ability to act as system thinkers.

We chose to study attitudes instead of behaviour in this work for some additional reasons. First, it is difficult to identify and measure relevant behaviour in this domain. While some work has attempted to understand what behaviours enable successful systems engineering processes (Williams and Derro, 2008; Davidz et al. 2004; Rhodes et al., 2008), yielding a large number of potentially interesting behaviours, few methods exist for choosing the most relevant or quantifying or measuring these behaviours in a meaningful way. Second, the use of attitude questionnaires is easier to scale to collect larger data sets. Large data sets enable more rigorous hypothesis testing, and stronger, more generalizable conclusions can be drawn from the data. How behaviour can be predicted by these attitudes remains a topic of future work.

One can argue that the distinction in attitudes discussed so far exists more generally between engineering and product design. We use the term 'design thinking' to encompass the plurality of human-centred design processes that seek to unpack the core values behind design decisions With this in mind, we chose SE as the representative process of engineering in the scale for two reasons. First, $\mathrm{SE}$ is a comprehensive and discipline-independent engineering approach. Education in SE is often seen as an extension to traditional engineering courses, and practical, real-world experience is also necessary for effective skill building. This definition of SE should be accessible to engineers with foundational backgrounds in any of the traditional engineering disciplines, making the scale applicable across different engineering contexts. Second, SE overlaps technical and human-centred disciplines. Systems engineers are often described as interdisciplinary, flexible, and creative (Brooks et al. 2011). They are emotionally intelligent, effective communicators, and have strong intuition about both technical and social factors that influence systems design and performance (Frank 2012; Christine Williams and Derro, 2008). Systems engineers are expected to integrate and apply engineering skills and professional skills like design thinking, contrary to engineering "stereotypes" that suggest a more conventional approach (Pennock and Wade 2015). Design attitudes should be familiar to experienced systems engineers and relevant to their work.

In the following study methodology, we describe an approach for testing the following hypotheses:

- Systems engineering attitudes and design attitudes are different

- Systems engineering and design attitudes are not mutually exclusive

- Systems engineering and design attitudes can be represented and measured in a valid and reliable Likert scale

Methodology and findings are discussed next.

\section{METHODOLOGY}

We use a mixed methods approach in the study. Qualitative analysis is used to identify and understand stereotypical attitudes about SE\&DT, and to develop statements reflecting these attitudes for scoring on a Likert scale. The scale is analysed quantitatively using exploratory and confirmatory factor analyses.

In this section, we describe a three-step method:

1. Thematic analysis of systems engineering research and professional handbooks and standards; design thinking research and resources; and works comparing the two approaches/similar themes

2. Creation of statements (items) to be endorsed on a 5-point Likert scale

3. Distribution of scale \& analysis

Each step is described next.

\subsection{Thematic analysis}

We adopt a deductive approach using existing representations of SE\&DT in the thematic analysis. This analysis serves primarily as a high-level, heuristic representation of differences for the purpose of exploring stereotypes quantitatively. Only three attributes are selected for study of a variety of possible options for representing systems engineering and design thinking. These themes were selected because they are commonly understood to be mutually exclusive, and the research objective is to test this assumption. Additional analysis would be useful for identifying other attributes and developing more sophisticated hypotheses, models, and scale items. 
We begin the analysis with themes derived from traditional representations of the design/engineering dichotomy.

The following themes were selected to represent systems engineering attitudes:

- Unambiguous problem definition, objectives, and requirements

- Analytical/data-driven

- Methodical/systematic

The following themes were selected to represent design attitudes:

- $\quad$ Ambiguous problem definition, objectives, and requirements

- Empathetic/relationship-driven

- Innovative/creative

These characteristics are not necessarily "opposites" or mutually exclusive, although they are often represented as such. The "methodical/systematic" engineering process is not the opposite of an "innovative/creative" design process and many systems engineers are both methodical/systematic and innovative/creative. Similarly, one can be both empathic/relationship-driven and analytical/data-driven, and research suggests that a human-centred approach is actually necessary for coordinating complex sociotechnical systems (Williams and Derro, 2008). Experienced systems engineers are also able to challenge assumptions about problems and constraints while working within process boundaries.

Classical systems engineering and operations research by Checkland (1981) describes this duality as systems practice and systems thinking. The application of systems thinking in systems engineering practice is described as part of soft systems methodology (Checkland and Scholes, 1990). Soft systems methodology is a sense-making approach to solving engineering problems that addresses human and social aspects of problem situations in addition to engineering objectives. Holwell (1997) describes soft systems methodology as "classic systems engineering with the transforming addition of human activity systems modelling." Our themes reflect this characterization by capturing "classic systems engineering" (i.e., methodical, analytical, and data-driven) attitudes and attitudes about humancentred (i.e., empathetic, innovative, and creative) modelling and design processes.

Pidd (1996) summarises the differences between "hard" engineering approaches and "soft" analytical approaches like design thinking along four dimensions: problem definition, model, the organization, and outcomes. From this work we take the following description of differences related to problem definition:

"Problems are social or psychological constructs that are the result of framing and naming (Schön, 1982). This contrasts with the view, common in engineering, that work begins once a need is established. Thus...in soft analysis, the work focuses on ends as well as means to those ends. In hard systems engineering, the idea is to provide "something to meet the need" and the concern is with "how [do we meet the need]...not what [is the need]?" (Checkland and Scholes, 1990)

A common attitude in engineering is that design problems are taken as given, along with their parameters, constraints, objectives, and requirements. These problems are unambiguous, involve known physical variables, and mathematical and simulation-based analyses are necessary and sufficient for solving them. In "soft analysis," problems, parameters, and solutions are ambiguous, and qualitative methods are used to consider social and psychological contexts while defining the design problem and engineering parameters.

A similar discussion of requirements definition approaches appears as part of a research agenda on the "top 10 illusions of systems engineering" (Pennock and Wade 2015). This work describes classical assumptions of systems engineering, and ways in which these assumptions are illusory in today's systems environment. Requirements definition is described as traditionally absolute and unambiguous:

"Traditional systems engineering assumes that there is a "right' or optimal answer....this is one of the major assumptions that often separates traditional systems engineering from systems thinking which embraces the soft, and often inconclusive, nature of systems. Systems engineering operates under the illusion that it is possible to specify unambiguous requirements using human language. Of course, experience tells us that it is quite common for reasonable people to hold differing interpretations of a requirement." (Pennock and Wade 2015)

The authors go on to describe systems engineering as traditionally mechanistic:

"Traditional systems engineering is blind to this human element, including culture and history. [In systems engineering] is implicitly assumed that these factors will not substantially influence 
outcomes. However, norms and values can affect both what potential solutions are considered and how a systems engineering program is executed." (Pennock and Wade 2015)

For this reason we include "empathetic" and "relationship-driven" as complementary dimensions of the design thinking process.

In addition to empathy-driven processes, design thinking also includes strategic and practical processes for the innovation of products and services within business contexts. Inspiration, creativity, iteration, and prototyping are human-centred processes for stimulating innovation and increasing business viability (Brown and Katz, 2011). Strategic and practical processes in systems engineering (we refer to these as "methodical/systematic") more closely resemble project management processes such as scheduling, budgeting, and change documentation.

\subsection{Scale development and subject populations}

Statements reflecting the six themes from Section 3.1 were written using language from professional, academic, and open-source materials on systems engineering and design thinking. These statements were included as items on a five-point Likert scale ranging from "1- strongly disagree" to "5- strongly agree". Over 100 unique items were examined in three different pilot tests. Of these, the 23 statements were selected for inclusion in the scale tested in the present paper; the $11 \mathrm{SE}$ items across the three SE themes are listed in Table 1 and the 12 DT items across the three DT themes are listed in Table 2.

The Likert scale questionnaire was distributed to two groups of participants. The first group consisted of a panel of 369 participants through the social media site Reddit. There currently exist few published articles where participants were recruited through Reddit to gauge reliably the quality of data collected through it. Using Reddit to recruit study participants is potentially advantageous for several reasons (Shatz 2017). First, it is possible to recruit large samples in a short amount of time. Second, Reddit's community of subforums, or "subreddits," makes it is possible to recruit participants from specific demographics and special interest groups. The second group consisted of a panel of 88 self- and peeridentified experts in systems engineering and design research. Individuals were recruited based on their participation in academic conferences and workshops for engineering design, and were asked to distribute the survey to others with similar interests and experience. The individuals represented include experts from academia, industry, and government, and many hold advanced degrees in engineering and/or design.

As noted earlier, we check the factor structure of the scale quantitatively using exploratory factor analysis and confirmatory factor analysis. The results are discussed next.

Table 1. Statements reflecting systems engineering attitudes

\begin{tabular}{|l|l|l|}
\hline \multicolumn{1}{|c|}{$\begin{array}{l}\text { Assume unambiguous problems, } \\
\text { objectives and solutions }\end{array}$} & Analytical/data driven & \multicolumn{1}{c|}{ Methodical/systematic } \\
\hline $\begin{array}{l}\text { I like to receive a detailed set of } \\
\text { requirements before beginning a } \\
\text { project. }\end{array}$ & I build simulations and/or models to test my ideas. & $\begin{array}{l}\text { I document every change I make } \\
\text { to my designs. }\end{array}$ \\
\hline $\begin{array}{l}\text { I generate better ideas when I have a } \\
\text { defined problem statement and } \\
\text { objectives. }\end{array}$ & I use quantitative methods to compare different ideas. & $\begin{array}{l}\text { I always compare my final design } \\
\text { to the initial project goals. }\end{array}$ \\
\hline $\begin{array}{l}\text { I can infer a customer's expectations } \\
\text { based on the project goals. }\end{array}$ & $\begin{array}{l}\text { I use mathematical modelling/analysis to predict whether } \\
\text { my designs will meet customer expectations. }\end{array}$ & $\begin{array}{l}\text { I evaluate designs based on cost } \\
\text { and schedule. }\end{array}$ \\
\hline & I make design decisions based on data/analytical results. & \\
\hline & $\begin{array}{l}\text { I evaluate the success of my designs using quantifiable } \\
\text { performance measures. }\end{array}$ & \\
\hline
\end{tabular}


Table 2. Statements reflecting design attitudes

\begin{tabular}{|l|l|l|}
\hline \multicolumn{1}{|c|}{$\begin{array}{c}\text { Assume ambiguous } \\
\text { problems/solutions }\end{array}$} & \multicolumn{1}{c|}{$\begin{array}{c}\text { Empathetic/relationship-driven } \\
\text { Innovative/creative }\end{array}$} \\
\hline $\begin{array}{l}\text { I am comfortable working with changing project } \\
\text { requirements. }\end{array}$ & I am an empathetic person. & $\begin{array}{l}\text { Iteration is an improvement of } \\
\text { a design rather than a setback. }\end{array}$ \\
\hline $\begin{array}{l}\text { I like to redefine or restructure the problems I am } \\
\text { given to work on. }\end{array}$ & $\begin{array}{l}\text { I like to speak directly with my customers to } \\
\text { ensure that my design meets expectations. }\end{array}$ & I am a creative person. \\
\hline $\begin{array}{l}\text { I like to find unconventional ways to solve } \\
\text { problems instead of relying on past methods. }\end{array}$ & $\begin{array}{l}\text { I like to interact with customers frequently } \\
\text { throughout the design process. }\end{array}$ & $\begin{array}{l}\text { I find inspiration for my work } \\
\text { in my everyday life. }\end{array}$ \\
\hline & I am a curious person. & $\begin{array}{l}\text { I use storytelling techniques } \\
\text { to understand the problems I } \\
\text { am given to work on. }\end{array}$ \\
\hline
\end{tabular}

\section{RESULTS AND DISCUSSION}

\subsection{Exploratory factor analyses}

All 23 items in Tables 1 and 2 were included in the EFA. The analysis was conducted on a data set consisting of 457 observations of these 23 variables (i.e., both data from groups were combined). Factors were extracted using maximum likelihood estimation. An orthogonal rotational method (varimax) was used because we did not expect the obtained factors to be correlated based on the theoretical evidence described in Section 3.1.

A factor solution was obtained by considering Kaiser's criterion (retaining factors with eigenvalues greater than one), the interpretability of obtained factor solutions, the internal consistency of the obtained factors, and model fit indices (Worthington and Whittaker, 2006). EFA was also used to inform the retention and removal of scale items. Items were removed if they did not load onto a distinct factor consisting of at least three items, or if they did not have a primary factor loading of 0.40 or above with no significant cross-loadings onto other factors.

We compared the two-factor model with a one-factor model, as the three-factor model suggested a third factor consisting of only two items with loadings greater than 0.40. In comparing these models, consideration of the relevant criteria resulted in a final scale comprised of two factors and 9 items. The two-factor model was determined to be the final EFA model because it yielded an interpretable factor structure with significant improvement over the 1 -factor model.

Model fit indices suggested that the two-factor solution was a relatively good fit to the data. The Root Mean Square Residual (RMR) value of 0.07 was below the suggested 0.08 cut-off for very good fit. The Root Mean Square Error of Approximation (RMSEA) value of 0.073 was above the recommended 0.06 cut-off value for "very good" fit, but below the 0.08 cut-off for "adequate" fit (Hu \& Bentler, 1999; Kline, 2010). While there is some disagreement regarding exact cut-offs for fit indices and the RMR estimate of model fit, the two-factor EFA model was determined to be the best model. This solution suggests two conceptually meaningful factors, reflecting the underlying systems engineering and design attitude constructs.

A total of 14 items were removed from the measure after failing to meet the minimum criteria. The final factor loadings for 9 items are provided in Table 3: 
Table 3. Final factor loadings (EFA)

\begin{tabular}{|c|c|l|}
\hline \multicolumn{2}{|c|}{$\begin{array}{c}\text { VARIMAX ROTATED } \\
\text { LOADINGS }\end{array}$} \\
\hline DESIGN & SYSENG & \\
\hline-0.125 & $\mathbf{0 . 6 3 6}$ & Use quantitative methods to compare ideas \\
\hline 0.184 & $\mathbf{0 . 6 7 6}$ & Predict whether designs meet expectations \\
\hline 0.049 & $\mathbf{0 . 5 5 3}$ & Make decisions based on data \\
\hline 0.039 & $\mathbf{0 . 5 3 6}$ & Evaluate success using quantifiable performance measures \\
\hline $\mathbf{- 0 . 4 7 9}$ & -0.004 & Like to redefine/restructure design problems \\
\hline $\mathbf{- 0 . 4 6 4}$ & 0.127 & Is a curious person \\
\hline $\mathbf{- 0 . 6 5 3}$ & 0.083 & Is a creative person \\
\hline $\mathbf{- 0 . 6 2 4}$ & 0.036 & Finds inspiration for work in everyday life \\
\hline $\mathbf{- 0 . 5 1 2}$ & -0.132 & Uses storytelling techniques \\
\hline
\end{tabular}

\subsection{Confirmatory factor analyses}

The two-factor model identified via exploratory factor analysis was cross-validated by a confirmatory factor analysis (CFA). The CFA establishes a measurement model for systems engineering and design attitudes and is a more rigorous test of underlying factor structure.

Before proceeding to the structural model depicted in Figure 1, we conducted a test of measurement invariance to establish that the same construct was being measured across the Reddit and expert samples. Configural invariance was tested by fitting the same set of indicators to latent constructs for each group (Marsh, 1993). We compared model fit indices and the loading of indicators onto constructs for the Reddit and expert groups to test the configural invariance of these constructs. Model fit indices suggested that the measurement model was a good fit for both groups. As shown in Table 3, RMSEA values were below the 0.08 cut-off and SRMR values were also at or below the 0.08 cut-off for both groups. Comparative Fit Index (CFI) and Tucker-Lewis Index (TLI) estimates for both groups are at or above the .90 cut-off value for good fit suggested by Kline (2010).

Table 3. Fit indices for measurement models

\begin{tabular}{|c|c|c|c|c|c|c|c|}
\hline Sample & Model & $\mathbf{x 2}$ & $\mathbf{d f}$ & $\mathbf{p}$ & $\mathbf{R M S E A}$ & $\mathbf{C F I / T L I}$ & SRMR \\
\hline $\begin{array}{c}\text { Reddit } \\
(\mathrm{n}=369)\end{array}$ & 1 factor & 182.72 & 27 & 0 & 0.18 & $0.44 / 0.25$ & 0.146 \\
\hline & 2 factor & 51.66 & 26 & 0.002 & 0.07 & $0.91 / 0.90$ & 0.064 \\
\hline & 1 factor & 95.67 & 27 & 0 & 0.17 & $0.62 / 0.50$ & 0.133 \\
\hline $\begin{array}{c}\text { Expert } \\
(n=86)\end{array}$ & 2 factor & 37.51 & 26 & 0.07 & 0.07 & $0.94 / 0.91$ & 0.07 \\
\hline
\end{tabular}

After establishing measurement invariance, we examined the relationships between latent constructs in the model proposed in Figure 1. 


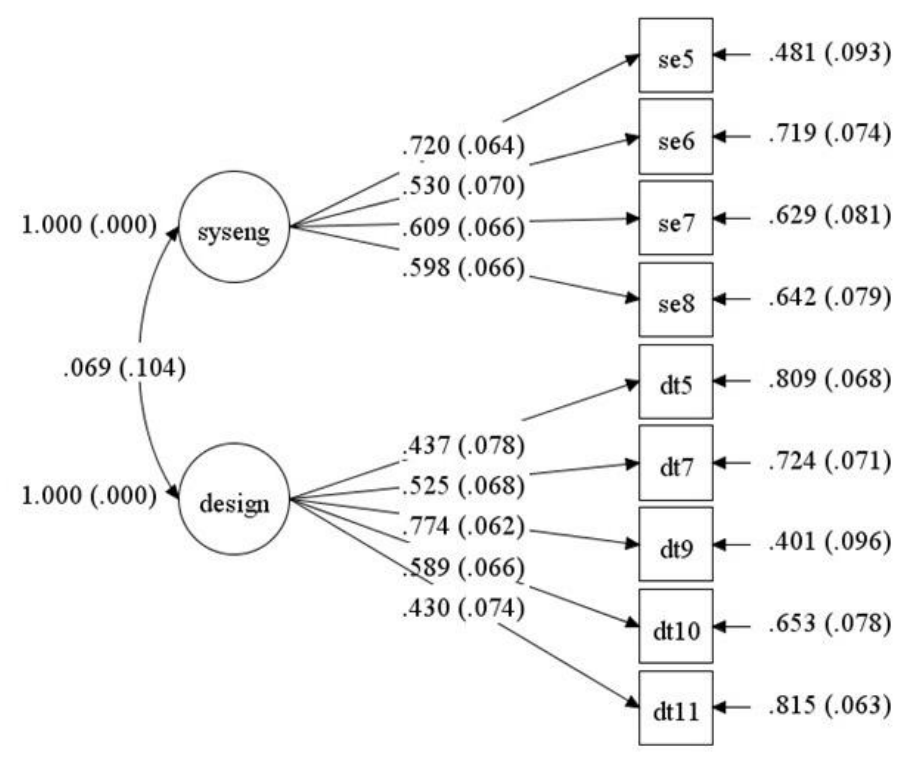

Figure 1: 2-factor model with parameter values and standard error

As shown in Table 3, the CFA shows an adequate fit to the data. The RMSEA of 0.07 is below the suggested 0.08 cut-off value. The CFI and TLI values of 0.91 and 0.90 , respectively, are at or above the .90 cut-off value for good fit suggested by Kline (2010). The SRMR value of 0.07 is below the 0.08 cut-off for good fit. The low correlation (0.069) between factors suggests that systems engineering attitudes and design thinking attitudes are independent. An individual can hold engineering attitudes, design attitudes, or both.

Overall, model fit indices indicated that the hypothesized relationships between observed variables and their corresponding latent constructs were a good fit to the data. All variables significantly loaded onto the same factor in the CFA as they had in the EFA, which provides psychometric support for the SE\&DT Scale and its factor structure using an alternative modelling approach.

These findings suggest that the "analytical/engineering" approach and the "human-centred/design" approach are not dichotomous, despite the common trope. Creative, relationship-driven attitudes can support innovation, collaboration, and co-design with other engineers and customers, while datadriven, analytical attitudes can support successful delivery of optimized solutions. The SE\&DT Scale shows promise as a useful way of measuring these attitudes. Future work will demonstrate how measuring these attitudes can be useful in practice.

\section{CONCLUSION}

In this work, we explore engineering attitudes, design attitudes, and the relationship between them using a psychometric approach. A goal of the research was to test the common perception that engineering and design attitudes are mutually exclusive. We explore these two constructs and their relationship through the development and validation of the SE\&DT Scale. Traditional representations of the engineering and design dichotomy were used to develop conceptual models of engineering and design attitudes, which were evaluated quantitatively using exploratory and confirmatory factor analyses.

Findings support the traditional representation of systems engineering and design attitudes as two distinct latent constructs, but do not support the stereotype that these two constructs are mutually exclusive. Consistent with contemporary observation and experience, engineering and design attitudes can be complementary; one can both be an engineer and think like a designer, and vice versa.

The SE\&DT Scale shows promise as a tool for capturing these attitudes along a spectrum. Subscale scores for engineering and design attitudes may be useful for identifying and balancing perspectives within engineering design teams. This possibility presents an opportunity for an observational study in the future. Another promising direction for this work is a behavioural study, in which scores on the SE\&DT Scale are used to predict behaviours with known implications for the success of systems engineering projects. Understanding the relationship between attitudes and behaviours in this context would be useful for education and training. 
Using Reddit to collect survey data had the unintended additional benefit of enabling concurrent collection of qualitative data for validating underlying theory and hypotheses, and also for improving them and refining vocabulary. Through user feedback, we received the following recommendations for improving the questionnaire:

- For some items, frequency (e.g., rarely $\rightarrow$ often) would have been a better indicator than agree/disagree;

- Additional items describing delegation of responsibilities would have been useful (e.g., "I direct people to do X simulation/analysis.")

Additional feedback about the questionnaire shared through open-response survey items, along with the Reddit comment sections, provided information that would be interesting to include in future qualitative analysis.

\section{REFERENCES}

Brown, T. and Katz, B. (2011), Change by Design: How Design Thinking Transforms Organizations and Inspires Innovation, Harper Business.

Brooks, JM, Carroll, JS and Beard, JW, (2011). "Dueling Stakeholders and Dual-Hatted Systems Engineers: Engineering Challenges, Capabilities, and Skills in Government Infrastructure Technology Projects." IEEE Transactions on Engineering Management, 58(3), pp.589-601. Available at: http://dx.doi.org/10.1109/TEM.2010.2058858.

Checkland, P. (1981), Systems Thinking, Systems Practice, John Wiley \& Sons, West Sussex, England, UK.

Checkland, P. and Scholes, J. (1999), Soft Systems Methodology in Action, John Wiley \& Sons, West Sussex, England, UK.

Darrin, M.A.G. \& Devereux, W.S., (2017). "The Agile Manifesto, Design Thinking and Systems Engineering." In Proceedings of the 2017 Annual IEEE International Systems Conference (SysCon). pp. 1-5. Available at: http://dx.doi.org/10.1109/SYSCON.2017.7934765.

Davidz, H.L., Nightingale, D.J. and Rhodes, D.H. (2004), "Enablers, Barriers, and Precursors to Systems Thinking Development: The Urgent Need for More Information", Proceedings of the International Conference on Systems Engineering/INCOSE.

Dym, C.L., Agogino, A.M., Eris, O., Frey, D.D. and Leifer, L.J. (2005), “Engineering Design Thinking, Teaching, and Learning", Journal of Engineering Education, Vol. 94 No. 1, pp. 103-120.

Frank, M. (2012), "Engineering Systems Thinking: Cognitive Competencies of Successful Systems Engineers", Procedia computer science, Vol. 8, pp. 273-278. Available at: http://www.sciencedirect.com/science/article/pii/S1877050912000580.

Greene, M.T., Gonzalez, R., Papalambros, P.Y. and McGowan, A.R. (2017), "Design Thinking vs. Systems Thinking for Engineering Design: What's the Difference?", Proceedings of the 21 st International Conference on Engineering Design, Vancouver, British Columbia, Canada.

Harvard Business Review (2015). The Evolution of Design Thinking. September 2015 Issue. Available at https://hbr.org/archive-toc/BR1509.

Holwell, S.E. (1997), Soft Systems Methodology and its Role in Information Systems, Ph.D. Dissertation, Lancaster University.

Hu, L. and Bentler, P. (1999), "Cutoff Criteria for Fit Indexes in Covariance Structure Analysis: Conventional Criteria versus New Alternatives", Structural Equation Modeling, Vol. 6, pp. 1-55.

Kline, R. (2010). Principles and Practice of Structural Equation Modeling (3rd ed.). Guilford Press, New York, NY. Marsh, H.W. (1993), "The Multidimensional Structure of Physical Fitness: Invariance over Gender and Age", Research Quarterly for Exercise and Sport, Vol. 64 No. 3, pp. 256-273.

McGowan, A. R., Daly, S., Baker, W., Papalambros, P. Y., and Seifert, C., (2013). “A Socio-Technical Perspective on Interdisciplinary Interactions During the Development of Complex Engineered Systems." In Proceedings of the Conference on Systems Engineering Research, Atlanta, GA, Mar 19-Mar 22, 2013.

McGowan, A.-M.R., Bakula, C. \& Castner, R.S., (2017). "Lessons Learned from Applying Design Thinking in a NASA Rapid Design Study in Aeronautics." In 58th AIAA/ASCE/AHS/ASC Structures, Structural Dynamics, and Materials Conference. Available at: http://dx.doi.org/10.2514/6.2017-0976.

Pennock, M.J. and Wade, J.P. (2015), "The Top 10 Illusions of Systems Engineering: A Research Agenda", Procedia computer science, Vol. 44, pp. 147-154. Available at: http://www.sciencedirect.com/science/article/pii/S1877050915002690.

Pidd, M. (1996), Tools for Thinking: Modelling in Management Science, Wiley, Chichester.

Rhodes, DH, Lamb, CT, and Nightingale, DJ., (2008). "Empirical Research on Systems Thinking and Practice in the Engineering Enterprise." Proc. of the IEEE International Systems Conference, Montreal, Canada, April 7-10, 2008.

Schon, D.A. (1982), The Reflective Practitioner: How Professionals Think in Action, Basic Books, New York. 
Shatz, I., (2017). "Fast, Free, and Targeted: Reddit as a Source for Recruiting Participants Online.” Social Science Computer Review, 35(4), pp.537-549. Available at: https://doi.org/10.1177/0894439316650163.

Souza, J. \& Barnhöfer, U., (2015). "Design Thinking: It's the Flare that Adds Another Dimension to Systems Engineering." Insight , 18(3), pp.25-27. Available at: http://doi.wiley.com/10.1002/inst.12044.

Williams, C. and Derro, M. (2008), "NASA Systems Engineering Behaviour Study.", NASA Office of the Chief Engineer, Washington, DC, USA.

Worthington, R., \& Whittaker, T. (2006). "Scale Development Research: A Content Analysis and Recommendations for Best Practices.” The Counseling Psychologist, 34, 806-838. 